\title{
Database Creation of a Development Project Inbauchi Town, Nigeria
}

\author{
I.Muhammed and A. Aliyu \\ Department of surveying and Geoinformatics Modibbo Adama University of Technology, yola
}

\begin{abstract}
A method is presented on the conversion of analogue cadastre to digital format, which is simple, faster and easy to use than the analogue method that is difficult to access and vulnerable to wear and tear. In addition to the digital map, development of cadastral database that allow querying of information is produced. This is convenient to both land managers and land ownerswho would want to know the current conditions of their plots. Utility managers could also find this useful by knowing additional information on each plot a priori. It is suggested that web-based GIS could facilitate even more on access to cadastral information.
\end{abstract}

Keywords: Cadastre, GIS, Layout, Database, Query

Submitted Date 14 June $2013 \quad$ Accepted Date: 19 June 2013

\section{Introduction}

The geospatial technology is a viable tool for management of natural resources, utilities and estates alike. This is due to the inherent advantage of using Geographic Information Systems (GIS) tools that allow a database to be stored, queried, retrieved, analysed and displayed optimally with very little effort.

Additionaldetails can be represented as layers of information to allow inter-comparison between different fields (ESRI-1, 2004).This provides easy access to a range of audience with added benefit of being able to be put online.

Database system is not only restricted to surveying field, but is widely used to create other information systems such as Police Information Systems (PIS), Environmental Information Systems (EIS), Agricultural Information Systems (AIS), Utility Information Systems (UIS) and land Information Systems (LIS) etc.

Geospatialinformation databases can be useful for any application if they provide the answers to the question relating to location of a particular object and attribute of a particular object containing various features (Ndukwe, 2001; Ekpette,2005).The advantages of database in GISis that they are centrally controlled, sheared, implemented and void of data redundancy since it is a direct user access instrument (Aronoff, 1991).

In Nigeria, conversion of analogue maps and parcels of land into digital format is becoming more popular. The Ministries of Lands and Surveys update their record and without doubt enjoy easy management of land parcels. This work focuses on a new development layout coded'DP31' in Bauchi Town, Bauchi State, Nigeria. The layout was surveyed and managed by the State Ministry of Lands and Survey and contains 512 parcels. These plots are residential, and facilities to be enjoyed by the occupants such as social and recreational facilities were also allocated spaces and have since been put to use.

Generally, layout surveys are first made on paper and then transferred to ground in order to achieve proper planning and decision making.However, managing these residential layouts is not without a hitch because the process of record keeping of land information files are in analogue form and often unsatisfactory in terms of storage and retrieval. This poses problems that include, 1) Poor maintenance and storage of information, 2) Inadequate data retrieval and manipulation capabilities, 3) High cost of production of map, 4) Time consuming process, and 5) The process of analyzing and anipulating the information contained on such analogue maps can be difficult and sometimes impossible.The aim of this paper is to create a functional database of these layouts and provide ability to query information. Attribute information to be queried are observable facts that include owner names, plot number, uses etc. The spatial data being a map of the study area will provide a wider view and location of the layout as well as information on adjoining facilities close to the perimeter. Querying provides information on linkages between attribute and spatial data in a database. 


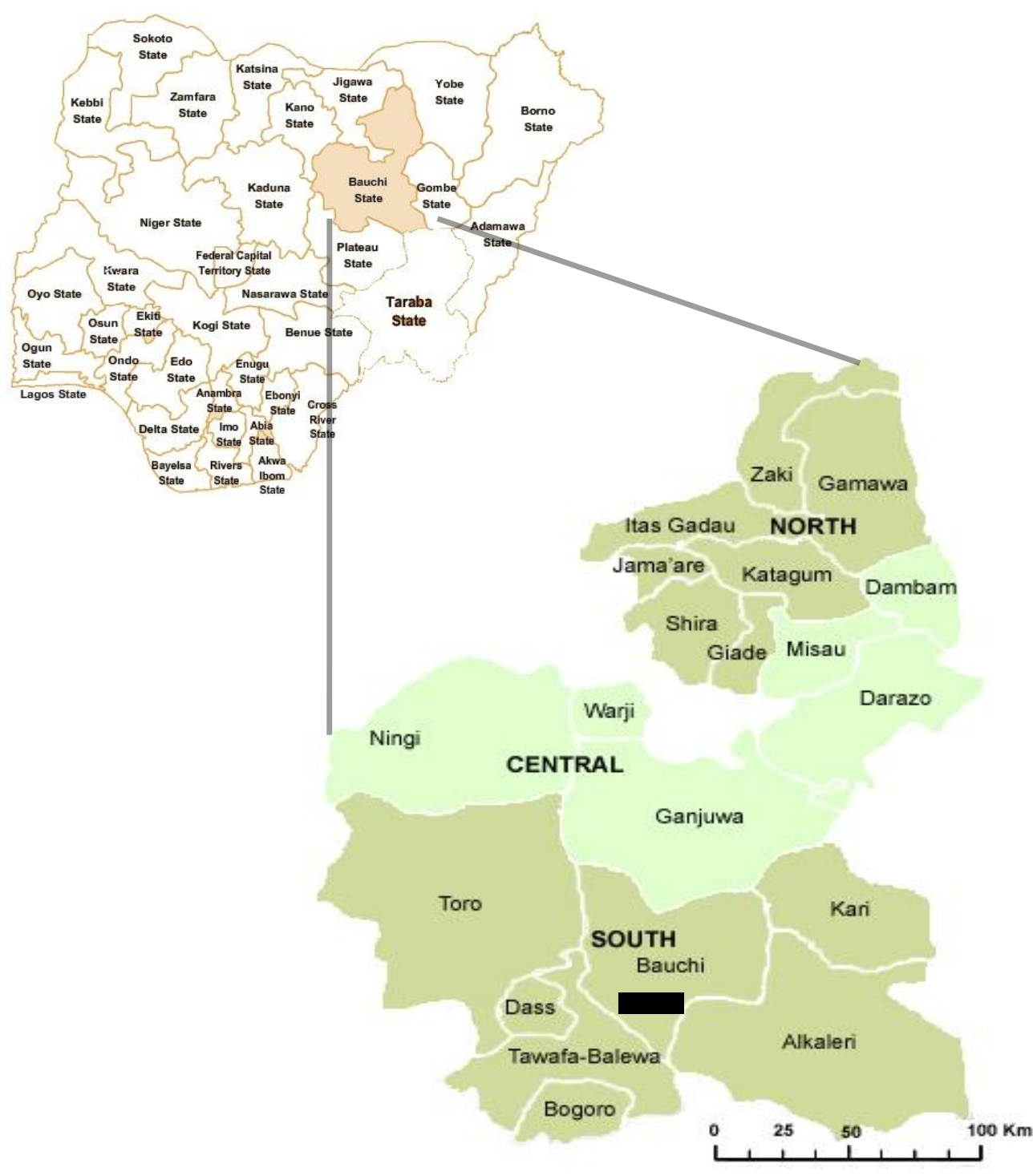

Figure 1: Map of Nigeria showing Bauchi State, and Bauchi State showing study area (black box). Image source: Map of Nigeria is from www.mapladia.com/ nigeria/bauchi and Bauchi State map is from www.bauchi-students.blogspot.com

\section{Study Area}

Bauchi State is located in the north-eastern geo-political zone of the country, bordering with Gombe, Taraba, Plateau, Kaduna, Kano, Jigawa and Yobe States (see figure 1). The state itself is divided into 3 zones that include north, central and southern zones. The capital city is Bauchi, synonymous with the state name and located in the southern zone. The study area, DP31 layout is located within the vicinity of the state capital, as indicated in figure 1. 


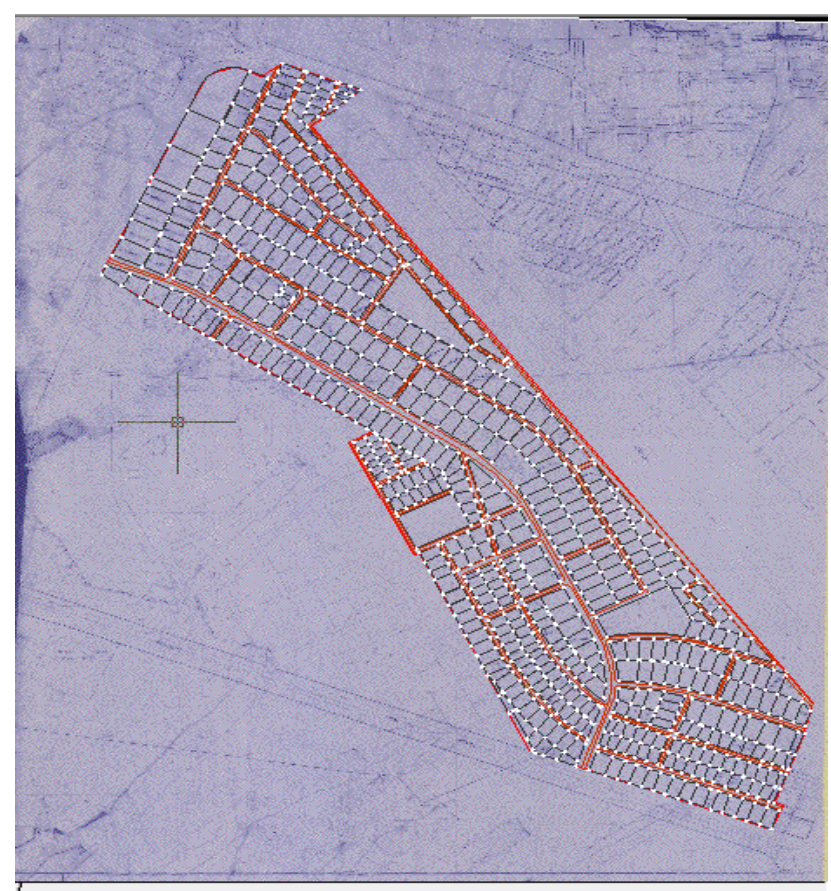

Figure 2: Plan of DP31 layout in Bauchi Town. Source: Ministry of Lands and Survey Bauchi.

\section{Data and Method}

The analogue DP31 layout plan maintained by the ministry of Lands and Survey and coordinates of some plots from coordinate register were used for this study (figure 2). The layout gives the actual information required for the database creation. During reconnaissance survey, two plots were chosen from which coordinates are used for georeferencing. These coordinates of the four corners of the plots were sourced out using the file number as shown in table 1 .

Table 1: Coordinates of two plots used for georeferencing.

\begin{tabular}{|l|l|l|}
\hline FILE NUMBER & EASTINGS (m) & NOTHINGS (m) \\
\hline & 6201.44 & 10821.28 \\
\hline & 6231.98 & 10882.37 \\
\hline & 6341.24 & 10802.48 \\
\hline BA/35749 & 6309.52 & 10751.96 \\
\hline & 7070.82 & 9701.07 \\
\hline & 7118.99 & 9699.30 \\
\hline BA/35563 & 7116.64 & 9645.85 \\
\hline & 7077.28 & 9648.78 \\
\hline
\end{tabular}

The collectedanalogue layout plan and attribute information for each plot are used to create a database. Two software packages were used in this study and that include ArcGIS 3.2a and AutoCAD 2012.The procedure adopted is shown as a flow chart in figure 3. The map was first scanned to produce a basemap from which further work is continued. To establish the relationship between the data displayed in the GIS environment and the real world, the coordinates shown in table 1 are used as tie points to georeference the map in the ArcGIS environment.

The resulting map is imported into AutoCAD and digitized to show clearly the layouts and road networks. The map was then reimported again into ArcGIS for the purpose of database creation. Query was generated by linking the digitized parcels with their respective attribute information. The result is a digital layout plan that shows parcel sizes, shapes and road networks. This can be queried to provide information on any plot. 


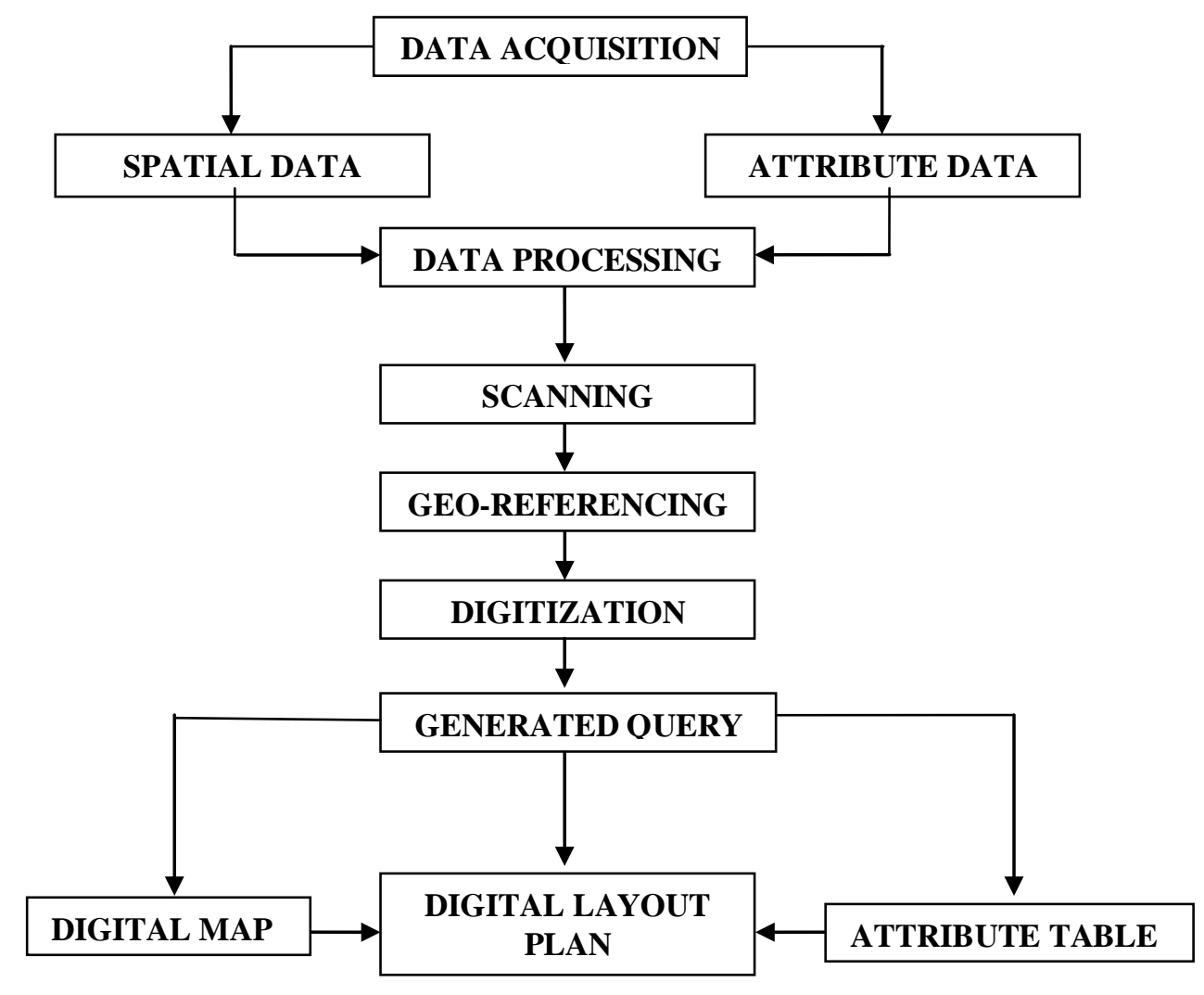

Figure 3: Flow chart of methodology

\section{Results and Discussions}

The outcome of database created are shown in figures 4, 5 and 6 . The yellow colours are the identifier colours, while blue are inactive. These figures show categories of usage and whether developed or not. Figure 4 shows parcels that are developed while figures 5 and 6 show usage as school and recreation respectively. It is possible to query other details for each plot such as Owner, Possession of Certificate of Occupancy (C of $\mathrm{O}$ ), Plot Number, Block Number, Area, Shape, Status of Development etc.

This paper shows that GIS technology can be used as interactive tool to visualise and interpret information pertaining land parcels. Gehlot and Hanssen (2008) have suggested that additional information such as vector data of roads canbe incorporated into the cadastre databases. Additionally, there could be a recognition if many users can have access to such database and query at the same time (Mikol, 2008). For example, a user can have access to his plot online to verify whether his $\mathrm{C}$ of $\mathrm{O}$ is processed or not. Similarly, one can check the status of parcels adjoining his plot so he can think of developing it or not. If a user finds that his plot is adjoining to a school, he may not develop the plot but rather sell it off to an interested buyer because the area can be noisy. 


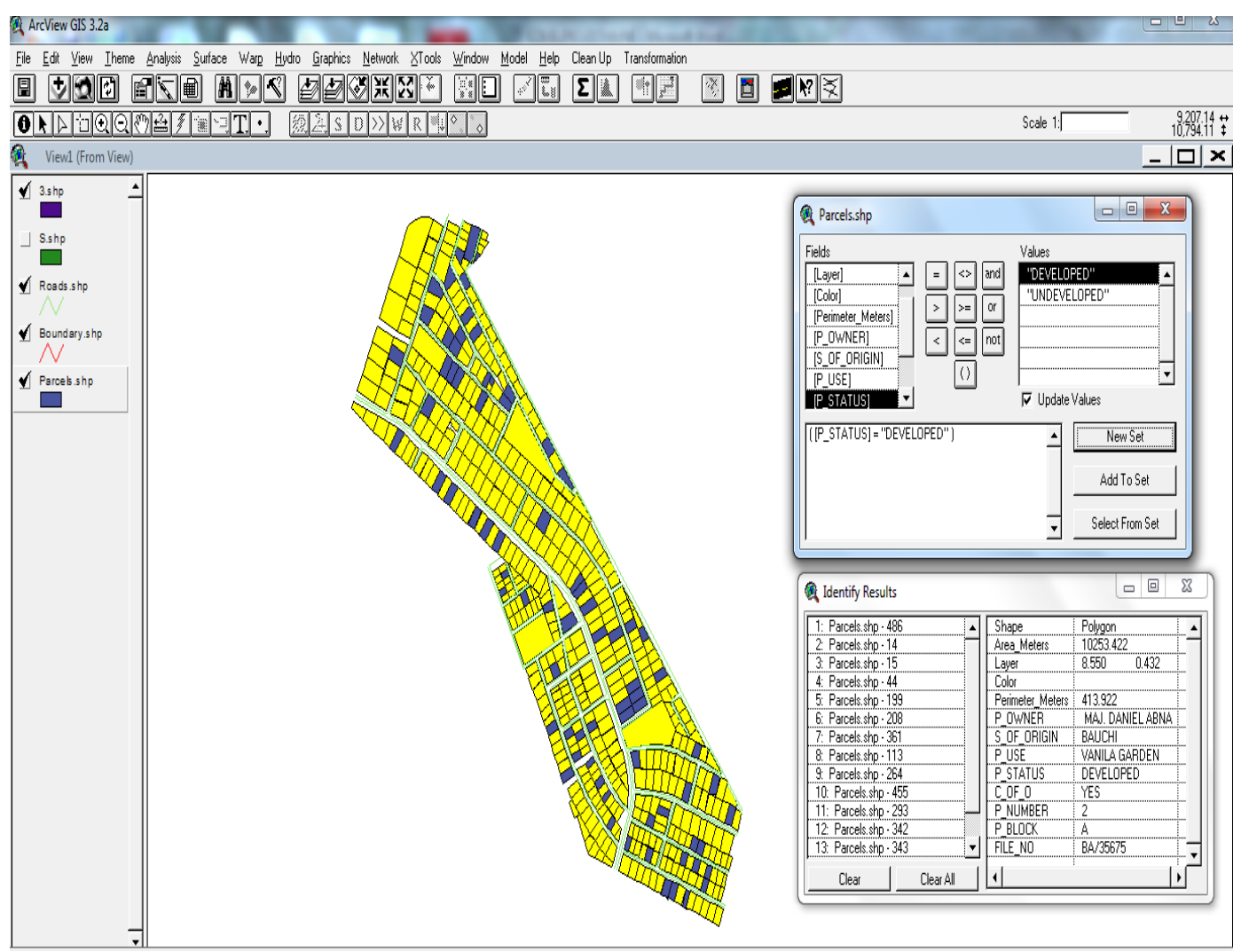

Figure 4: Parcels that have been developed are shown in yellow. The top small inlet window shows plot category as developed, while the lower window show details and particulars of the owner. Blue colours are parcels used for other purposes.

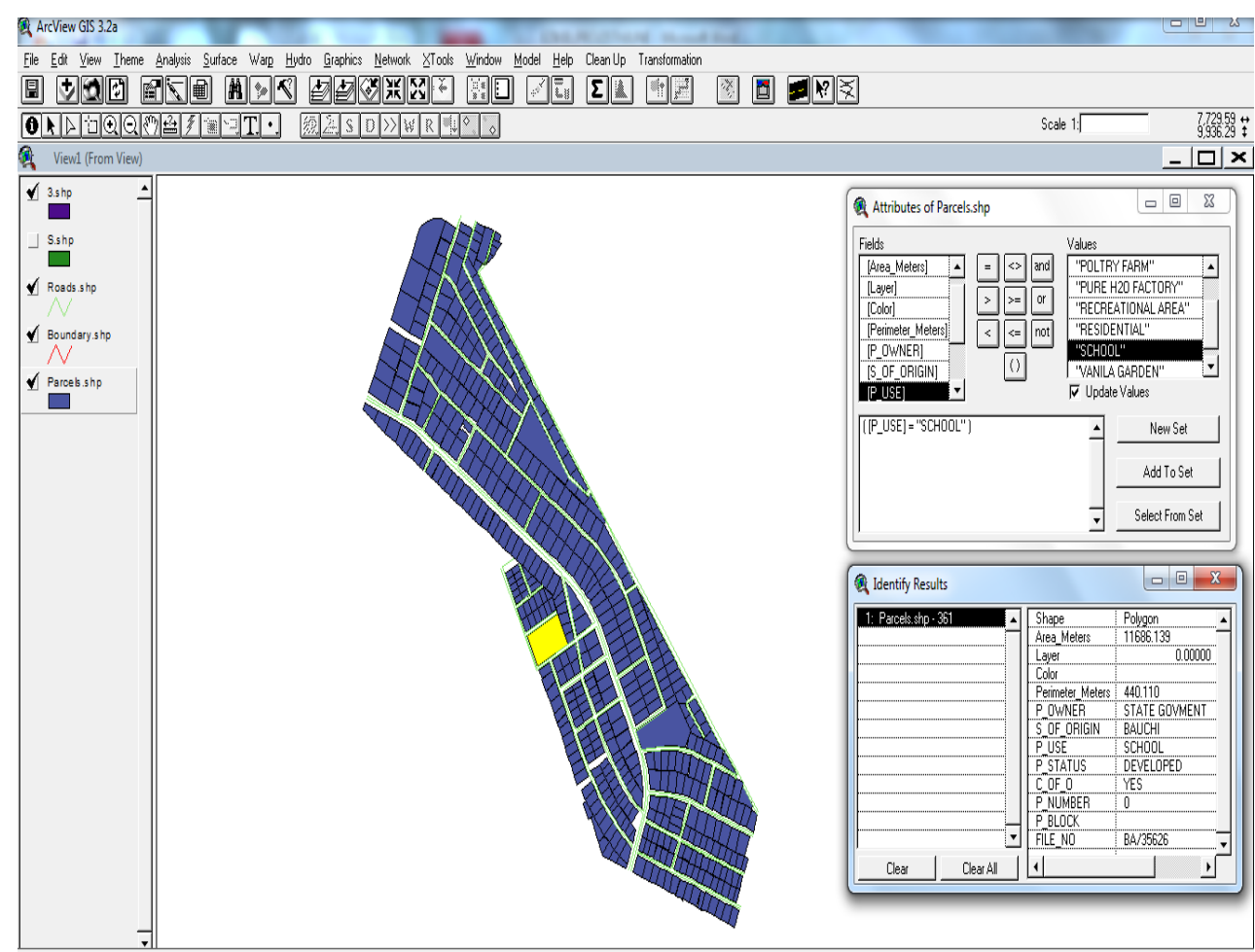

Figure 5: A parcel allocated for the purpose of school is shown in yellow. The top small inlet window shows plot use as school, while the lower window show details and particulars of the school owner, which is State

Government. Blue colours are parcels used for other purposes. 


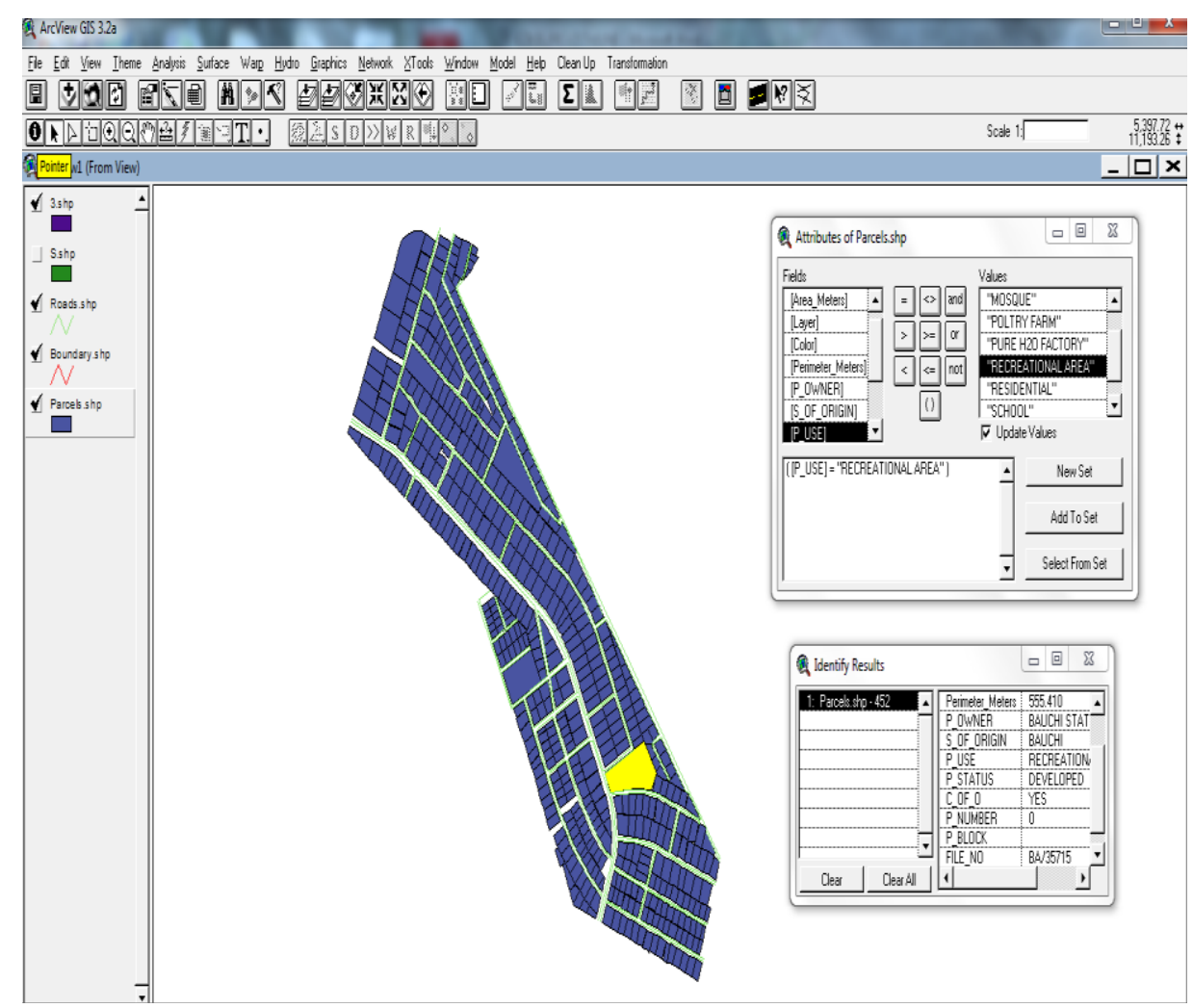

Figure 6: A parcel allocated for the purpose of recreation is shown in yellow. The top small inlet window shows plot use as recreational, while the lower window show details of the plot as well as the owner, which is State

Government. Blue colours are parcels used for other purposes.

\section{Conclusion}

The use of GIS technology in digital mapping and database creation of a survey layout has been employed. The analogue map has been digitized and concurrentattribute information of each parcel has been linked to the parcels. This make it possible to query the database for any particular information needed at any point in time. The ability to visualize the queries and maps is,by far a positive contrast to the old analogue map, which was difficult to access and vulnerable to wear and tear.This database created would help in proper management of the layout and provide ease to occupants who would want to know the condition of their plots at various times. Web-based databases could provide additional advantage to users wherever they are. This research shows that the Nigerian cadastral system that has been redundantly kept in analogue format can be converted and managed easily.

\section{Acknowledgement}

We acknowledge Ministry of Lands and Survey, Bauchi and Mr Ezikiel Hamman for the data used in this paper.

\section{References}

[1]. Aronoff, N.O. (1991). Principles and Application of Geographic Information System. Lecture Notes. Department of Surveying and Geo-informatics, University of Lagos.

[2]. Ekpette, R.A. (2005), Principles of Geographic Information System for Land Resources Assessment. Nigeria Journal of Surveying and Geo-informatics, vol.1, No.1 pp.17-40

[3]. ESRI Environmental Systems Research Institute, Inc. (2004) ESRI Shapefile Technical Description.

[4]. Gehlot, S. and Hanssen, R. F. (2008).Monitoring and Interpretation of Urban Land Subsidence Using Radar Interferometric Time Series and Multi-Source GIS Database. In Remote Sensing and GIS Technologies for Monitoring and Prediction of Disasters. Springer-Verlag Berlin, pp. 142

[5]. Mikol, R. M. (2008). Extending the Functionality of the Consumer-Grade GPS for More Efficient GIS and Mapping Applications: In Remote Sensing and GIS Technologies for Monitoring and Prediction of Disasters. Springer-Verlag Berlin, pp. 161

[6]. Ndukwe, O. (2001). Cadastral Database: An Essential Component of the Fundamental Datasets of a National Geospatial Data Infrastructure. Proceedings of Technical Session of the $37^{\text {th }}$ Annual General Meeting and Conference of NSDI, Owerri pp. 19-24 